\title{
REGIMES DE INFORMAÇÃO NA SOCIEDADE DA INFORMAÇÃO: UMA CONTRIBUIÇÃO PARA A GESTÃO DA INFORMAÇÃO ${ }^{1}$
}

\author{
Roberto José Gervásio Unger \\ Isa Maria Freire
}

\section{Resumo:}

O avanço alcançado pelas tecnologias de comando e comunicação, atuais tecnologias de informação e comunicação alçaram a Humanidade numa condição jamais vista, modulando, inclusive, o sistema social, que tem na informação e no conhecimento os recursos que movem não somente a economia no planeta mas o cotidiano dos seres humanos. O trabalho visa aproximar os conceitos de sociedade da informação, regimes de informação, sistemas de informação e linguagens documentárias. Busca trabalhá-los em conjunto visando uma forma de, dentro da perspectiva dos regimes de informação, que são modos de produção informacional dominantes em um contexto social, dar uma contribuição aos gestores de informação. As tecnologias de informação e comunicação são vistas como os dispositivos de conectividade que aumentam a abrangência e alcance dos limites dos regimes de informação e também como parte da solução de problemas para os sistemas de informação. Argumenta que se entendemos os regimes de informação como ambientes onde convivem seres humanos e a informação, os sistemas de informação idealizados a partir da concepção dos regimes de informação atenderiam com melhor precisão às demandas informacionais.

\section{Palavras-chave:}

Sociedade da informação; Regimes de informação; Sistemas de informação; Linguagens documentárias, Gestão da informação

\section{Regimes of information in Information Society: a contribution to information management}

\section{Abstract:}

The advancements reached by command and communication technologies, today's information and communication technologies, have placed mankind on a condition never seen before; it has also modulated the social system, which finds in both information and knowledge the resources which move not only the economy on the Planet, but also the day-to-day of human beings. This work approaches the concepts of information society, regimes of information, information systems, and documentary languages. It seeks to work them out as a whole, aimed at a way of - within the perspective of information regimes which are the modes of dominant informational production - in a social context to contribute to the information managers. The information and communication technologies are viewed as the connectivity that increases the comprehensiveness as well as the outreach of the limits of regimes of information, and also as a part of problem-solution for the information systems. This work also points out that if the regimes of information are understood as environments wherein both human beings and information dwell together, the information systems idealized from the concept of regimes of information would meet with highest precision that the information needs.

\section{Keywords:}

Information society; Regimes of information; Information system; Documentary languages; Information management

\footnotetext{
${ }^{1}$ Texto baseado na dissertação de mestrado de Roberto José Gervásio Unger, defendida no Programa de Pós-Graduação em Ciência da Informação do convênio IBICT - Universidade Federal Fluminense e orientada pela professora doutora Isa Maria Freire. Foi
}

(c) Revista Digital de Biblioteconomia e Ciência da Informação,Campinas, v.2, n. 2, p. 87-114, jan/jun. 2008- ISSN: 1678-765X. 


\section{INTRODUÇÃO}

Este trabalho representa o resultado do desenho de um quadro teórico no campo da gestão da informação, a partir dos conceitos de Sociedade da informação, Regimes de informação, Sistemas de informação e Linguagens documentárias. Embora se apresentem como conceitos próximos, tem autonomia relativa em seu entrelaçamento, o que torna complexas suas relações e trocas recíprocas em um quadro teórico. Mas, ao mesmo tempo, apresentam uma urdidura original, pois a informação, não obstante ser objeto de diferentes interpretações em cada um desses conceitos é o fio condutor do trabalho.

Em nossa interpretação, a Sociedade da informação abriga em seu interior os Regimes de informação, os quais abrigam os Sistemas de informação que, por sua vez, trazem em seu interior as Linguagens documentárias. Essa é a metáfora que representa a forma como idealizamos o desenho desse quadro teórico: os conceitos estão separados por seus próprios enunciados e abordagens, que representam ou explicam ações em seus respectivos campos; mas podem ser re-unidos no tear da Ciência da Informação, como urdiduras para a formulação de políticas de gestão da informação.

Nosso propósito foi lançar uma luz sobre um quadro conceitual pertinente às ações de informação em organizações sociais. Nosso viés se revela na implícita e necessária entidade informação e, também, na relevância dada à conectividade crescentemente presente na comunicação vigente no regime de informação atual - que, queiramos ou não, nos abriga e nos desabriga também. A perspectiva tecnológica é uma vertente tão importante quanto a informação, neste trabalho, pois a ideologia dos regimes de informação se estabelece pela forte presença da tecnologia que dá suporte ao regime, sustentando os sistemas de informação e ganhando força e importância no acesso, com as linguagens documentárias.

Ao tornar a informação a principal matéria-prima para o aumento da produtividade, em nível mundial, a sociedade contemporânea tornou também necessária a organização e gestão desse insumo. Com o desenvolvimento da tecnologia digital, os suportes onde a

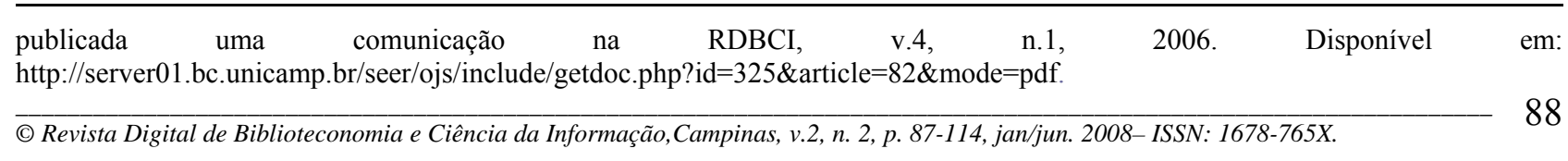


informação se substancia ganharam diferentes formatos, sendo criando um universo em paralelo e, de certa forma, sem controle, ocasionando o que se costuma chamar de explosão informacional. Sendo assim, de um regime industrial formado pelas tecnologias de comando e comunicação, passamos para um regime de produção que se qualifica como sociedade da informação e comunica através de tecnologias cada vez mais digitais.

Assim, tecemos nosso quadro teórico a partir dos conceitos de sociedade da informação, regimes de informação, sistemas de informação e linguagens documentárias. Buscamos trabalhá-los em conjunto, na perspectiva dos regimes de informação como modos de produção social e com o propósito de contribuir para uma visão crítica dos sistemas de informação, ao destacar o contexto social onde esses sistemas estão inseridos. Nossa argumentação é a de que se entendermos os regimes de informação como ambientes onde convivem seres humanos e estoques de informação, poderíamos desenhar sistemas que atenderiam com maior precisão às demandas informacionais da sociedade. É nesse sentido que entendemos como premente a necessidade de identificarmos as características dos regimes em vigor na sociedade contemporânea, para aprofundarmos a discussão e proposição de políticas de gestão da informação.

\section{SOCIEDADE DA INFORMAÇÃO}

Nos primórdios da manifestação da informação como fenômeno sociológico, econômico e político, as tecnologias de controle e comunicação - as atuais tecnologias de informação e comunicação - já tinham seu caminho pavimentado por uma questão de segurança nacional em função dos conflitos entre as nações e, também, como poderemos observar, pelo avanço inexorável do desenvolvimento da ciência. Fato é que, desde os anos 1970, algumas teses começaram a tratar do assunto e as denominações "Sociedade pós-industrial” (BELL, 1973; MASUDA, 1982), “Terceira onda” (TOFFLER, 1981), “Sociedade informática", (NORA, MINK, 1980; SHAFF, 1992), "Sociedade póscapitalista ou do conhecimento", (DRUCKER, 1994), "Sociedade da pós-informação ou digital", (NEGROPONTE, 1995), "Sociedade informacional”, (CASTELLS, 1999), foram surgindo e algumas nações - entre elas o Brasil - criaram programas nacionais para a sua implantação. Pela primeira vez na história da humanidade, os fatores de 
produção tradicionais - terra (matéria-prima), capital e trabalho — deixaram de ser considerados os principais criadores de riqueza (OCDE, 1999).

As tecnologias de informação e comunicação, que podemos considerar como o parque tecnológico que dá suporte ao trânsito intenso da informação, tiveram início nos movimentos de automação das máquinas, que provocavam intensas modificações nos meios fabris dos países centrais. As idéias sobre comunicação e controle que Wiener partilhava com Claude Elwood Shannon e Warren Weaver, versavam sobre mensagens de homens para homens, de homens para máquinas e de máquinas para máquinas. Segundo Wiener, a Sociedade só pode ser compreendida através de estudo de mensagens e das facilidades de comunicação de que disponha e que as mensagens entre homens e máquinas, entre as máquinas e os homens e entre a máquina e a máquina estão destinadas a desempenhar papel cada vez mais importante. (Cf. WIENER, 1984, p.16).

A retroalimentação ou feedback (ou seja, a capacidade de poder ajustar a conduta futura em função do desempenho pretérito) é um conceito antigo, mas que ganhou ímpeto com o novo tratamento teórico da comunicação e as possibilidades de comunicação máquina a máquina. Foi nesse contexto que Bush idealizou seu conceito de máquina computadora que era, segundo Wiener, puramente mecânico. Nele, fazia-se a integração por meio de discos gigantes, que se engrenavam uns nos outros por atrito, e o intercâmbio de entradas e saídas entre esses discos era tarefa desempenhada pelo clássico trem de eixos e engrenagens. As concepções de Bush para a máquina computadora assemelhavam-se às de Babbage $^{2}$, mas este ainda não dispunha de meios técnicos para desenvolvê-la nos primórdios do século XIX, eram muito aquém de suas ambições (cf. WIENER, 1984, p.147). Entretanto, Bush idealizou uma categorização dos meios tecnológicos de armazenamento da informação como indicativo de um sistema social em que o ser humano teria a possibilidade de armazenar e acessar a informação de maneira ótima. Para lidar com esse problema, ele propõe o "memex", antecipando o que viria a ser a tecnologia (estrutura e função) de um terminal de computador em rede.

\footnotetext{
${ }^{2}$ Entre 1802 e 1822, o matemático e engenheiro inglês Charles Babbage apresentou um projeto à Sociedade Real de Astronomia, baseado nos conceitos de Müller, Bouchon, Falcon, Jacques e no desenvolvimento que Jacquard efetuou com seus teares. Preocupado com os erros contidos nas tabelas matemáticas de sua época, Babbage construiu um modelo para calcular tabelas de funções (logaritmos, funções trigonométricas, etc.) sem a intervenção de um operador humano, que chamou de "máquina das diferenças".
} 
Consideramos a reflexão de Bush como importante fator no que diz respeito ao advento de um novo tipo de sistema social baseado na informação, que se consolidou algumas décadas depois nas interpretações de autores como Bell (1973), Masuda (1982), Castells (1999), Webster (1995), que apontam para a forte presença da tecnologia no advento da sociedade da informação, muito embora concordem que este sistema social não depende somente da tecnologia para existir. Entretanto, para efeito de argumentação, verificamos que a influência da tecnologia na consubstanciação da Sociedade da informação é muito forte, haja visto o legado de Wiener e Bush. A noção do senso comum sobre Sociedade da informação identifica a abundância de informação, possibilitada pelas tecnologias de informação e comunicação, em especial a Internet, como a essência dessa Sociedade.

Na nossa interpretação é um sistema social que resulta das inovações das tecnologias de informação e comunicação que, concomitantemente, com a relevância da informação como matéria-prima, provoca profundas alterações nos diversos setores da sociedade, muito embora sua importância e influência seja desigualmente distribuída, no que diz respeito aos diferentes estratos sociais e regiões geográficas. Nessa nova ordem econômica mundial, que se anuncia nas explanações científicas e na economia das tecnologias digitais, é que ocorre a "nova relevância de um fenômeno antigo" (WERSIG e NEVELING, 1975 citados por Freire, 2001) e o regime de informação, com seus sistemas de informação e linguagens documentárias, inicia sua hegemonia sobre o regime industrial, na sociedade contemporânea.

\section{REGIMES DE INFORMAÇÃO}

Frohmann (1995) trabalha o construto regime de informação com o apoio da "Teoria de atores e redes" (TAR) de Bruno Latour, definindo como regime de informação qualquer sistema estável ou rede nos quais os fluxos informacionais transitam por determinados canais - de específicos produtores, via estruturas organizacionais específicas, para consumidores ou usuários específicos. Redes de rádio e televisão, distribuidoras de filmes, publicações acadêmicas, bibliotecas, são alguns nós de redes de informação ou elementos de regimes de informação específicos. 
Entre os vários componentes dos regimes de informação há que se considerar o próprio ambiente onde eles se instalam. Nos regimes de informação assinalamos diversos elementos, entre os quais se destacam os artefatos tecnológicos, materializados nas tecnologias de informação e comunicação que permitem a conectividade; os estoques de informação, que, por sua vez, subdividem-se em dinâmicos e estáticos (BARRETO, 1996; PEREIRA, 1998); os produtores de informação; os canais de comunicação da informação (formais e informais); os sistemas de recuperação da informação, com sua missão precípua de organização, armazenamento e transferência da informação; as linguagens documentárias que representam as informações disponíveis; e, principalmente, os seres humanos com suas necessidades informacionais.

González de Gómez, por sua vez, trabalha o conceito de regime de informação na concepção de dispositivo ${ }^{3}$ de Michel Foucault, definindo-o como
“"Um modo de produção informacional dominante numa formação social, conforme o qual serão definidos sujeitos, instituições, regras e autoridades informacionais, os meios e os recursos preferenciais de informação, os padrões de excelência e os arranjos organizacionais de seu processamento seletivo, seus dispositivos de preservação e distribuição". (GONZÁLEZ DE GÓMEZ, 2002, p.34)"'”

Assim, a abordagem de regimes de informação apresenta diferenças em Frohmann e em González de Gómez (autores em que nos apoiamos nesta pesquisa): enquanto esta última aborda o regime de informação sob o aspecto político, Frohmann detêm-se nos artefatos tecnológicos, na viabilidade do trânsito informacional por e através do meio físico. Certamente o construto tem forte ligação com as políticas de informação oriundas das instituições governamentais e a sociedade organizada, contudo é no meio ambiente de trocas materiais (econômicas, tecnológicas, culturais) que ocorrem as relações entre seres humanos com necessidades informacionais e fontes de informação relevantes, em um regime de informação.

Destarte, na nossa interpretação a extensão do conceito de regime de informação apresenta essa dupla composição: um meio ambiente físico onde se instalam os artefatos tecnológicos e as políticas informacionais que regulam sua produção e comunicação. O

\footnotetext{
${ }^{3}$ Etimologicamente, o termo latino dispositio seria a tradução do termo grego diathesis; é definido na filosofia moderna como aquilo que facilita, faz algo possível ou limita as possibilidades de algo.
} 
conceito de "regime de informação" demarcaria um domínio amplo e exploratório, no qual a relação entre a política e a informação - não pré-estabelecida - ficaria em observação, permitindo incluir tanto políticas tácitas e indiretas quanto explícitas e públicas, micro e macropolíticas, assim como permitiria articular, em um plexo de relações por vezes indiscerníveis, as políticas de comunicação, cultura e informação (cf. GONZÁLEZ DE GÓMEZ, 2002, p.35-36).

$\mathrm{Na}$ nossa interpretação, regimes de informação podem ser definidos como ambientes ${ }^{4}$ onde convivem os sistemas de recuperação da informação, as linguagens documentárias, e os seres humanos com suas necessidades informacionais. As ofertas informacionais dos regimes de informação são advindas de meios de comunicação de massa, pela mídia eletrônica, instituições de ensino e pesquisa, organismos governamentais e nãogovernamentais, agências de fomento, associações de classe, organizações religiosas etc.

Nesse sentido, a figura abaixo, adaptada de Wilson, Streatfield, Wersig (1982), é uma representação descritiva do que consideramos a maneira como os regimes de informação estão inseridos no espaço social:

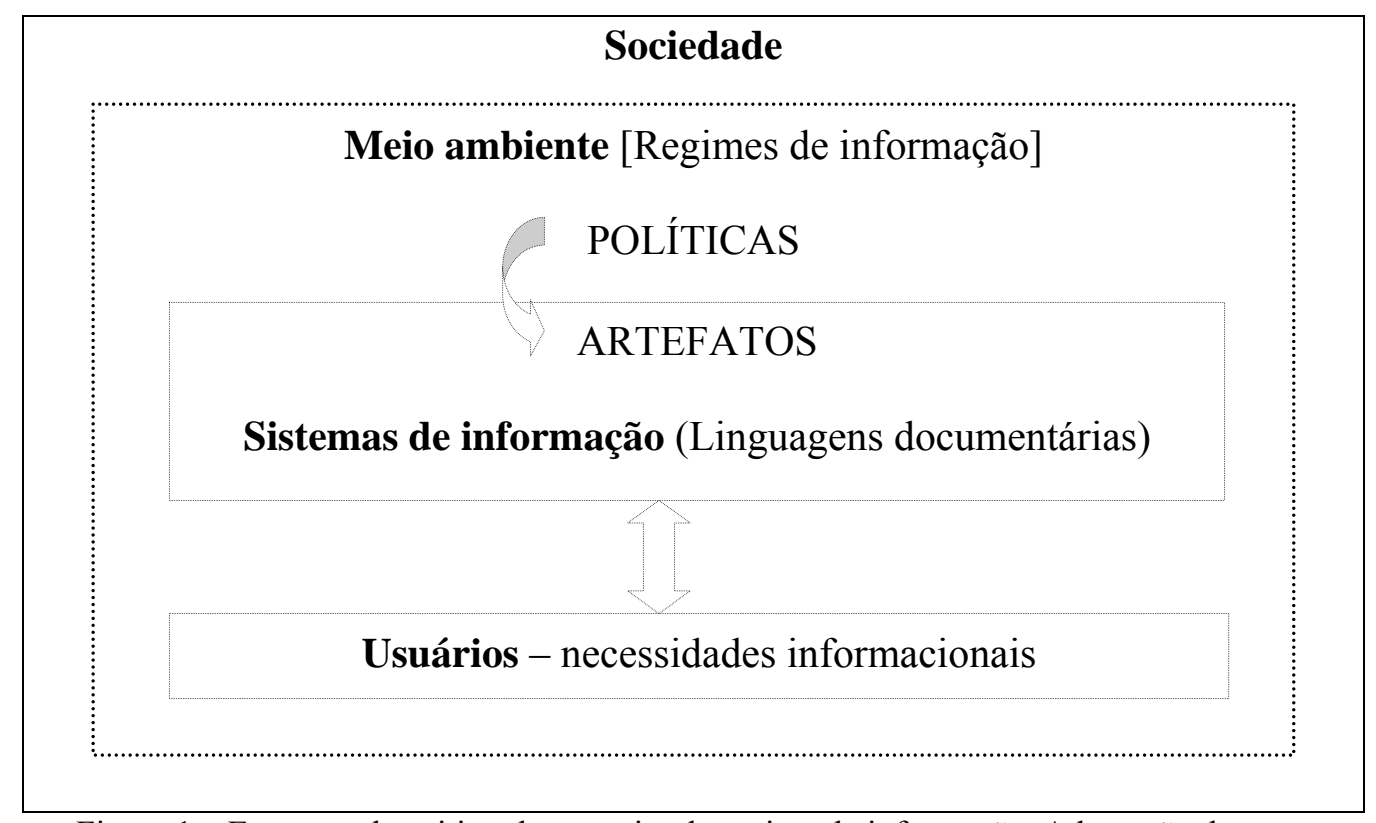

Figura 1 - Esquema descritivo do conceito de regime de informação. Adaptação de Streatfield, Wilson, Wersig, 1982

Frohmann afirma que, atualmente, a clara representação dos regimes de informação como se originam e se estabilizam, como determinam as relações sociais e como são exercidas as formas de poder em e através deles — se apresenta como um "legítimo e

\footnotetext{
${ }^{4}$ Cf. Dicionário Aurélio, ambiente significa “que cerca ou envolve os seres vivos e as coisas” (p.82).
} 
premente objetivo na pesquisa em política de informação" (FROHMANN, 1995). Para ele,

\begin{abstract}
“"...Descrever um regime de informação significa catalogar [mapear] o polêmico processo que resulta da tentativa da inquieta estabilização dos conflitos entre os grupos sociais, interesses, discursos, com os eqüitativos artefatos científicos e tecnológicos. A estrutura teórica do estudo das políticas de informação, deve ser suficientemente rica para compreender as complexidades destas relações. (FROHMANN, 1995)"'”
\end{abstract}

Nossa premissa é que os regimes de informação são a substância que dão o caráter principal a um sistema social que passou por diferentes e longas fases até chegar ao estágio atual. A investigação e o estudo sobre o ambiente físico em que se dão os regimes de informação são um grande desafio. A nosso ver, para dar significado à ambientação dos regimes de informação é necessário, no mínimo, discorrer sobre algumas vertentes, sejam elas: o ambiente, a economia ou mercado e o poder exercido pelos grupos dominantes sobre os dominados. Entre os limites e bordas que contornam um regime de informação está o ciberespaço ${ }^{5}$ que é o local onde, virtualmente, transita a informação. $\mathrm{O}$ termo acabou por se transformar num sinônimo de Internet, mas o conceito subjacente é mais lato. De uma maneira geral ciberespaço é o espaço de convergência de todos os meios de comunicação - áudio, vídeo, telefone, televisão, cabo e satélite.

Há algumas décadas atrás, Herbert Marshall McLuhan previu o aparecimento de uma rede de telecomunicações que se tornaria na tradução eletrônica do sistema nervoso humano. (McLUHAN, 1977) A aldeia global viabilizada pela Internet possibilitou o acesso de milhões de pessoas a uma partilha de informação, experiências e atividades que ultrapassam as barreiras tradicionais do espaço, tempo, língua e cultura. E nesse meio ambiente cabem muitos regimes de informação, cada um com sua política e seus artefatos: sistemas de recuperação e linguagens documentárias que podem aproximar a informação de seus possíveis usuários, na sociedade.

\title{
4 SISTEMAS DE INFORMAÇÃO
}

\footnotetext{
${ }^{5}$ Ciberespaço é um termo inventado pelo escritor canadense William Gibson, no seu romance Neuromancer, para descrever o espaço constituído por todos os computadores e respectivos serviços, ligados entre si.
} 
Nosso objetivo é dar ênfase aos sistemas de informação como componentes fundamentais de uma organização social cuja principal característica é o intenso fluxo informacional, possibilitado, em grande parte, pelos estoques de documentos (em variados suportes) que viabilizam o armazenamento, a organização e o tráfico da informação, e também pela proliferação da tecnologia de informação e comunicação que embasam e permitem o trânsito de informações.

É proposital a omissão, neste trabalho, dos sistemas nacionais de informação idealizados pela UNESCO, denominados NATIS (sigla para Sistema Nacional de Informação). Não é nossa intenção apontar as iniciativas pontuais das cooperações entre os órgãos e dos recursos disponibilizados para a criação destes dispositivos. A proposta é discutir a maneira que a gestão da informação é realizada nos sistemas de informação e as relações imbricadas com os usuários. É importante esclarecer que o vocábulo informação é trabalhado em nossa argumentação como componente fundamental de um modelo de sociedade que se denomina Sociedade da Informação, justamente por ter como núcleo de suas características organizacionais, a informação.

Nos sistemas de informação, a informação representa o conhecimento, vinculando-se à sua materialidade ( $c 0 i s a==$ documento; dado==informação), conferindo-lhe um estatuto tangível. Originalmente referida com base no esquema tradicional de comunicação emissor, canal, mensagem, receptor — o enfoque sobre informação associado à transferência permite, atualmente, contemplar o usuário numa dimensão mais ampla que o inclui como participante ativo do processo informacional. (LARA, CONTI, 2003, p.26)

Este aspecto é observado em nossa concepção de que os sistemas de informação estão contidos nos regimes de informação, configurando-se em um componente que se distingue pela sua original capacidade de armazenar e organizar os estoques de informação, que são o leit-motiv da Sociedade da Informação. Ademais que, em nossa abordagem, os sistemas de informação são tidos como uma tecnologia social que pode auxiliar aos seres humanos na busca na melhoria da qualidade de vida.

A Teoria Geral de Sistemas (TGS) surgiu com os trabalhos do biólogo Ludwig von Bertalanffy, publicados entre 1950 e 1968. A TGS não busca solucionar problemas ou 
tentar soluções práticas, mas sim produzir teorias e formulações conceituais que possam criar condições de aplicações na realidade empírica. Há uma concordância ampla de que sistema é um modelo de natureza geral, isto é, um análogo conceitual de alguns traços razoavelmente universais de entidades observadas. ${ }^{6}$ Amaral, citado por Araújo, mostranos com eficiente acuidade uma definição de sistema onde "sistema é todo conjunto de dois ou mais elementos que interagem. [...] Quando se visualiza desde o Universo até uma partícula atômica, temos o que se chama de uma visão sistêmica" (AMARAL,1977 apud Araújo, 1995)

A visão sistêmica aborda o mundo como um conjunto de sistemas e subsistemas em implicações de conter/estar contido. Para Maciel, a noção de sistema é bastante primitiva, no sentido de que não se deixa facilmente definir em função de conceitos mais simples. Como toda noção primitiva, trata-se de conceito de grande extensão, quer dizer, aplica-se a quase tudo o que existe e é complexo e organizado. Sistema, então, seria um conjunto de elementos qualquer ligado entre si por cadeias de relações de modo a constituir um todo organizado. (MACIEL, 1974, p.13).

Em princípio, os elementos constitutivos de um sistema podem ser de qualquer tipo, desde indivíduos ou grupos até objetos ou funções, uma vez que haja entre eles uma ordem, uma interdependência, um caráter relacional (cf. LAKATOS, 1987). Em um sistema social cada um dos indivíduos que interatuam tem uma função a desempenhar. Quando suas funções são reconhecidas e apreciadas publicamente, denominam-se papéis. Cada pessoa interatuante em um sistema social tem um ou vários papéis para desempenhar. As unidades que interagem em um sistema social podem ser indivíduos (fundamentalmente), grupos ou organizações de pessoas.

De modo geral, os sistemas de informação têm intensa troca com o meio ambiente, pois a sua realização depende única e exclusivamente do fazer e da utilização informacional propiciados pelas necessidades informacionais dos seres humanos. As necessidades informacionais são tão ou mais fortes e prementes que as necessidades fisiológicas (LE

\footnotetext{
${ }^{6}$ De acordo com Bertalanffy, um sistema pode ser entendido como um conjunto de elementos em interrelação entre si e com o ambiente.
} 
CODIAC, 1996; FIGUEIREDO, 1996), outorgando aos sistemas de informação uma característica impar nas atividades humanas.

Ao analisar a tipologia sistêmica, Afanasiev enumera as divisões clássicas ocidentais partido do pressuposto de que todos são tipos de sistemas integrais:

"'Mecânicos, físicos, químicos, biológicos; sistemas naturais, sistemas artificiais
criados pelo homem (máquinas, mecanismos e obras) e sistemas de ordem mista
formados por componentes de ordem natural e artificial ("homem-máquina").
Existem sistemas materiais e ideais, etc. (AFANASIEV, 1977 apud Araújo,
1995)"”"

Tentando buscar o entendimento necessário para a relação existente entre os sistemas integrais de Afanasiev e os sistemas de informação, em uma dimensão onde a relação do meio ambiente, onde se situam os sistemas de informação, com o meio social, onde estão localizados os seres humanos e suas necessidades informacionais, trazemos a contribuição de Tefko Saracevic, que nos apresenta um cenário da Ciência da informação, que tem a recuperação da informação (information retrieval) como um de seus pilares básicos. Na obra de Saracevic identifica-se que o objetivo de qualquer sistema de informação é alcançar "relevância" nas informações oferecidas aos seus usuários, pois relevância é usada "no contexto de sistemas de informação, em particular, e nos processos de comunicação em geral." Relevância significa o fornecimento de informação a tempo, regularmente, de forma efetiva e eficiente, capaz de eliminar informação não relevante pois "se não é relevante, não é informação" e pode ser traduzida como "uma medida de contato efetivo entre a fonte e o destinatário" (SARACEVIC, 1970). Assim, consideramos que a abordagem de Saracevic, e sua nítida preocupação com a "relevância" da informação, apresenta uma forte evidência do "olhar sistêmico" que os gestores de informação deveriam utilizar em seus campos de atividades.

$\mathrm{Na}$ interpretação de sistema de informação, tal como o sistema integrado proposto por Afanasiev, consideramos que a relevância seria o diferencial e que permitiria a integração total com o meio ambiente ao atender às necessidades informacionais dos seres humanos. Assim, o usuário, entendido como ser social, deve ser situado no centro do sistema de informação e não no seu exterior. O sistema de informação seria a ferramenta de que ele dispõe para interagir com o exterior (meio ambiente) onde ele habita e, nesse sentido, ele tem que ocupar o núcleo do sistema utilizando os meios informacionais de que dispõe 
para manter-se "vivo" dentro do regime de informação que, por sua vez, utiliza o conceito de relevância para que esse equilíbrio ocorra de forma harmoniosa para que a vida sobreviva.

Nesse esforço, o ser humano produz informação que irá alimentar o sistema e que, mais tarde, irá servir como combustível para o próprio sistema. Esse não é um movimento mecânico, pois o sistema de informação, mesmo sendo um artefato técnico, é componente de um amplo e complexo sistema (o regime de informação) que deve se integrar com o meio ambiente que o envolve. O ser humano é a parte nuclear deste sistema integral, na medida em que fornece a informação que alimenta o sistema e abastece a si próprio, nesse processo.

Dentro do nosso raciocínio, os sistemas de informação, idealizados para atender as necessidades informacionais do ser humano propiciam a transformação do conhecimento acumulado em novos conhecimentos e estes, por sua vez, são organizados em novos estoques de informação. Assim, os sistemas de informação são, seguramente, um dos sustentáculos do novo modelo social representado pela Sociedade da Informação, possibilitando tornar mais factível o acesso à informação (matéria-prima para a produção de bens e serviços) e contribuindo para a melhoria da qualidade de vida dos seres humanos.

\section{LINGUAGENS DOCUMENTÁRIAS}

Nossa intenção, neste trabalho, foi estudar as linguagens documentárias procurando situálas no contexto da relação entre regimes, sistemas e usuários da informação. Pois na medida em que fomos desenvolvendo a pesquisa-dissertação, percebemos as linguagens documentárias como instrumentos de intermediação entre o conhecimento organizado em estoques de informação e os seres humanos.

As linguagens documentárias são instrumentos de representação do conhecimento contido em estoques de informação, sendo sua principal finalidade a indexação para armazenamento, recuperação e transferência desses estoques de informação. A necessidade de efetivar este mecanismo deu-se, inclusive, pelo fato que a linguagem natural contida nos documentos não permitia a sua recuperação eficiente, daí a 
importância de se criar uma linguagem que permitisse o controle dos estoques de informação a serem armazenados. Sem a correta utilização das linguagens documentárias na tarefa da indexação, os documentos estariam relegados ao desuso em função única e exclusiva de sua não localização.

Outro aspecto não menos importante das linguagens documentárias, é que elas constituem o principal elo entre o usuário e o conhecimento organizado em forma de estoques, nos diversos tipos de agregados de informação ${ }^{7}$. Seria impraticável viver num mundo em que não existisse a possibilidade de se organizar documentos. É necessário ter acesso ao conhecimento já produzido para que se possa construir novo conhecimento e a informação que o representa. As linguagens documentárias têm essa função, permitem organizar o conhecimento acumulado estabelecendo pontes, atalhos e caminhos entre a documentação já estruturada e armazenada e o que está a ser criado. No momento em que as tecnologias digitais têm sido utilizadas na comunicação, as metodologias de construção de linguagens documentárias são referidas como meios para tratar também universos não exclusivamente bibliográficos, como sites na web, conteúdos de manuais técnicos, de CD-ROMs de distintos assuntos, etc. Essas metodologias são essenciais à arquitetura da informação (cf. LARA, 2004).

A denominação linguagem documentária, além de se referir ao conjunto dos diferentes tipos de instrumentos especializados no tratamento da informação bibliográfica (sistemas de classificação enciclopédicos ou facetados e tesauros), designa, de modo mais amplo e completo, a linguagem especialmente construída para organizar e facilitar o acesso de transferência da informação. Na visão de González de Gómez (1995) as linguagens documentárias são meta-informação, ou seja, informação sobre a informação. Elas cumprem este papel com a finalidade de abrir os acessos à informação consolidada. A Ciência da informação surge após a constituição e expansão de um novo campo de interesses e investimento social ao qual pertence essa abordagem que diferencia as informações do que seja a informação sobre as informações e que também considera o conhecimento, a comunicação, os sistemas e usos da linguagem como objetos de pesquisa científica e tecnológica. 
Para Tálamo, “uma linguagem documentária é simultaneamente um modo de organização e uma forma de comunicação da informação” (TALAMO, 1997), mas, de uma forma geral, uma linguagem documentária representa uma ferramenta, ou tecnologia intelectual $^{8}$. Poderíamos pensar as linguagens documentárias como filtros que permitem a representação do significado das linguagens naturais. O caráter científico deu à linguagem uma força tal que, hoje, pode-se dizer que ela se constitui na chave de acesso do homem moderno às leis do funcionamento social (cf. KRISTEVA, 1969)

No âmbito documentário representar conteúdos para constituir informação significa recortar, segmentar. Como qualquer segmentação, ela não é neutra, mas tributária de hipóteses de organização. Além disso, conscientes ou não, desde que usamos a língua estamos utilizando convenções: a língua é o primeiro sistema modelizante a partir do qual todos os outros sistemas derivam. Também não é necessariamente unívoca a interpretação do usuário, sujeito que também tem suas convicções e está apto a formular hipóteses, tanto quanto o produtor do sistema de representação. Com efeito, para que se possa falar de transmissão de informação documentária é necessário formular hipóteses (e explicitá-las) razoavelmente compartilhadas pela comunidade de usuários do sistema que se propõe (cf. LARA, 2002, p.132; ARAÚJO, 1974, p.184; FOSKETT, 1980, p.16).

Assim, e a nosso ver, as linguagens documentárias seriam a última instância entre o usuário e os sistemas de informação - materializando seu acesso e comunicação com o conhecimento - , que são vistos aqui como o conjunto maior do universo informacional onde estão contidos os estoques de informação.

Na concepção de Dahlberg (1979), o futuro das linguagens de indexação (termo genérico para designar todos os tipos de thesauri, incluindo listas de cabeçalhos de assunto, listas

\footnotetext{
${ }^{7}$ Segundo BARRETO (1996) os agregados de informação são constituídos por bibliotecas, centros de documentação e sistemas de informação, os quais organizam, armazenam e transferem estoques de informação para usuários, na sociedade.

${ }^{8}$ Entendemos as tecnologias intelectuais como aquelas que "aumentam e modificam nossas capacidades cognitivas". Estão incluídas, nessas tecnologias, sistemas lógicos, de cálculo, técnicas de comunicação e de tratamento e representação da informação. Dentre elas, destacam-se, atualmente, as tecnologias intelectuais em suporte digital que "favorece[m], ainda, o desenvolvimento e manutenção da inteligência coletiva, pois exteriorizando uma parte de nossas operações coletivas as tornam [...] públicas e partilháveis” (LEVY, 1993, p.41).
} 
de descritores e, algumas vezes, até sistemas de classificação), não deve ser julgado do ponto de vista de um "desenvolvimento natural" necessário ou desnecessário, mas de preferência de um ponto de vista de responsabilidade social e intelectual. Os recursos humanos e financeiros em cada país deveriam ser utilizados para esse fim. Contudo, ao investir em linguagens documentárias, deveríamos verificar a sua utilização prática dentro de um processo de busca e recuperação por diferentes tipos de usuários.

\section{UMA ABORDAGEM DO PROBLEMA}

Como temos argumentado, sendo responsabilidade social do campo científico da Ciência da Informação "facilitar a comunicação do conhecimento [representado pela informação] para quem dele necessita" (WERSIG e NEVELING, 1975 apud, 1995, p.133), os profissionais da informação deveriam considerar como fundamento para suas atividades um quadro de trabalho no qual as linguagens documentárias e os sistemas de recuperação da informação se relacionem ao regime de informação vigente, com o propósito de atender às necessidades de informação de grupos de usuários na sociedade.

Foi nessa direção — atendimento a demandas de usuários por sistemas de informação, mediatizado por linguagens documentárias, em um dado regime de informação — que caminhamos ao longo da nossa pesquisa-dissertação. Lembramos, aqui, que os regimes são compostos fisicamente por:

- estoques de informação (que se constituem de linguagens documentárias e sistemas de informação);

- diretrizes políticas que direcionam os conteúdos informacionais abrigados nos sistemas de informação;

- os seres humanos e suas necessidades informacionais;

- o ambiente social em que estoques de informação e os seres humanos que os utilizam se inserem;

- os mecanismos de distribuição do acesso à informação;

- os meios físicos que permitem o ir e vir da informação (conectividade ${ }^{9}$ ).

${ }^{9} \mathrm{O}$ termo conectividade refere-se às redes de comunicação ou ao ato de comunicação entre computadores e terminais e, também, do ponto de vista técnico-educacional, às atividades de instalação, configuração e manutenção de redes de 
Nos regimes de informação encontramos a totalidade da ambiência entre o conjunto dos itens que dividem este espaço: os seres humanos e as políticas de informação, bem como os estoques de informação formados pelos sistemas de informação. Aos sistemas de recuperação da informação cabe a responsabilidade social de disponibilizar os estoques de informação e também propiciar a acessibilidade às informações armazenadas.

As unidades de informação (bibliotecas, centros e sistemas de informação e de documentação) são instituições voltadas para a aquisição, processamento, armazenamento e disseminação de informação de interesse para determinados grupos de usuários (cf. IBICT, 1989 apud Tarapanoff, Araújo Júnior, Cormier, 2000). No contexto da recuperação da informação deve haver um processo de seleção de conteúdos relevantes para o usuário. Assim, simplesmente copiar um arquivo de um disco não é recuperar informação, nem tampouco assistir a um programa de televisão durante o qual o telespectador não exercita o controle sobre o que está sendo mostrado. Uma biblioteca (unidade de informação) é o melhor exemplo de uma instituição voltada à recuperação seletiva. Ninguém vai até ela para ler uma coleção inteira, mas para procurar algo seletivamente, frequentemente algo que satisfaça um conjunto de necessidades informacionais altamente individualizadas (MEADOW, 1992 apud ORTEGA, 2002).

Baseado nesse quadro teórico, a nossa argumentação é de que o reforço dado pelas tecnologias de informação e comunicação ao campo da documentação, de uma maneira geral, é uma importante contribuição no que diz respeito à organização física da informação. A questão logística de armazenar e organizar a informação e torná-la apta para o uso passa, inevitavelmente, pelas tecnologias que permitem a acessibilidade remota, entre outras. Os sistemas de informação devem, então, aparelhar-se com tecnologias digitais disponíveis no mercado para se organizarem de modo a atender a comunidade de usuários onde estejam inseridos utilizando a conectividade. $\mathrm{O}$ viés tecnológico é imprescindível, o que acarreta a necessidade de recursos financeiros que possibilitem a aquisição dos equipamentos necessários. Existem inúmeras tecnologias digitais disponíveis que garantem uma performance razoável para os sistemas de

computadores abrangendo equipamentos, sistemas e aplicativos (hardware e software). (Ver http://www.cefetce.br/Ensino/Cursos/Tecnico/Conectividade/Index conect.htm). Contudo, em nossa interpretação, é a conectividade que estabelece o padrão exigido para as unidades de informação que seriam adequadas ao modelo de sistema que idealizamos, baseado no Sistema dinâmico integral de Afanasiev. 
informação cumprirem seu papel de coleta, tratamento, organização, disponibilização e disseminação da informação.

A informação é, então, fator preponderante nas relações humanas no modelo social da Sociedade da Informação, o que garante aos regimes de informação importância e relevância na formação de cidadãos livres e aptos para o convívio social. Por outro lado, os regimes de informação não são per se garantia de estabilidade política e integração social. Conforme nos relata Frohmann (1995), a dominação sobre a informação por determinados grupos - e como esta se dá esta em relação a raça e classes sociais, por exemplo —, deveria ser estudada, para sabermos como melhorar estas relações e alcançar um nível mais eficiente de gestão e uma distribuição mais equânime da informação.

Ademais, González de Gómez (2002) ao descrever a Sociedade da Informação, diz que esta poderia ser entendida como a sociedade em que o regime de informação caracteriza e condiciona todos os outros regimes sociais, econômicos, culturais, das comunidades e do Estado. Assim, a sustentabilidade de um modelo de sistema social como o da Sociedade da Informação está diretamente ligado às possibilidades de acesso à informação: o ser social que "migrou" da Sociedade industrial para a Sociedade da informação deve ter condições de responder aos novos imperativos relativos a esta nova estrutura de relações e de produção. E este ser social necessita de suporte informacional para que possa realizar suas aspirações e aquelas que a própria sociedade demanda.

É assim que, no nosso entendimento, a conectividade ganha aspecto relevante no conjunto de elementos que formam o regime de informação da Sociedade da informação, o qual é amplamente beneficiado na medida em que as conexões e acessibilidade se multiplicam permitindo a formação de uma "teia mundial de informação" que ultrapassa as dimensões territoriais e culturais das nações. Se entendermos os regimes de informação como modos de produção informacional, deveríamos gerenciar as unidades de informação e os sistemas de informação de maneira a promover uma integração entre o sistema de informação e o meio ambiente circundante. Então, a gestão da informação poderia contribuir para a integração entre os sistemas e os regimes de informação e destes com a formação social, para atendimento às necessidades informacionais dos usuários. 


\subsection{Uma pesquisa exploratória}

Para conhecermos situações reais nas quais nossa perspectiva sobre os sistemas de informação poderia ser aplicada, deliberamos realizar uma pesquisa exploratória na cidade do Rio de Janeiro - RJ, sendo o campo da pesquisa constituído por uma amostra não-probabilística intencional (cf. MARCONI e LAKATOS, 2002) do conjunto de unidades de informação e na qual foram incluídas bibliotecas universitárias, públicas e privadas, e bibliotecas populares, públicas. Nossa idéia foi analisar comparativamente a infra-estrutura tecnológica desses três tipos de unidades de informação, considerando principalmente a disponibilidade ou não da conectividade [ligação com a Internet]. Estes sistemas de informação servem a públicos distintos, pois as suas finalidades são diferenciadas no que tange as populações que as circundam, ou, melhor dizendo, aos usuários que utilizam seus serviços. Foram selecionados 7 Instituições de Ensino Superior ( 3 públicas e 4 privadas) e 2 bibliotecas públicas:

- Universidade Federal Fluminense (UFF)

- Universidade Federal Rural do Rio de Janeiro (UFRRJ)

- Universidade Federal do Rio de Janeiro (UFRJ)

- Universidade Salgado de Oliveira (UNIVERSO)

- Centro Universitário da Cidade (UniverCidade)

- Universidade Veiga de Almeida (UVA)

- Pontifícia Universidade Católica do Rio de Janeiro (PUC-Rio)

- Universidade Cândido Mendes (UCAM)

- Biblioteca Euclides da Cunha (BEC)

- Biblioteca Pública do Estado do Rio de Janeiro (BPERJ).

\subsection{Procedimentos e resultados}

A técnica de pesquisa que empregamos consistiu na coleta de dados através de questionário aplicado aos dirigentes de sistemas de informação das instituições consultadas. As questões foram formuladas como um questionário com perguntas abertas e fechadas, de modo a auferir o emprego e utilização das tecnologias digitais de informação e comunicação nos sistemas consultados. Na questão aberta, solicitamos um 
resumo sobre vantagens e desvantagens das tecnologias digitais de informação e comunicação nos sistemas de informação.

Utilizamos sete variáveis que, de acordo com nosso entendimento, demonstraram o nível de relacionamento dos sistemas de informação com o ambiente em que estão inseridos. Para nossa argumentação, o nível de maior relacionamento com o ambiente em que os sistemas de informação estão inseridos pode ser medido conforme a sua conectividade com a rede mundial de computadores - a world wild web, mais conhecida como Internet.

A primeira variável do questionário trata da automação de processos técnicos na unidade de informação, o que lhe garantiria agilidade no acesso (remoto ou presencial) pelos usuários. Observou-se que todas as unidades empregam tecnologias digitais no processamento técnico da informação, ou seja, estão atendendo à exigência tecnológica do regime de informação dominante na sociedade em relação à organização da informação.

$\mathrm{Na}$ segunda variável, a ênfase foi dada à conectividade, quando procuramos saber a disponibilidade de serviços automatizados para os usuários o que, a nosso ver, está estreitamente ligado à acessibilidade remota por meio digital. Apenas uma das unidades de informação, a Biblioteca Euclides da Cunha, não oferece serviço automatizado para atendimento ao usuário. Trata-se de uma biblioteca popular.

Ainda no âmbito da acessibilidade, a terceira variável aborda o uso da indexação utilizando linguagem documentária pelas unidades de informação consultadas, outro item de extrema relevância na Sociedade da Informação, uma vez que, em conjunto com as tecnologias digitais, permitem a busca e recuperação rápidas da informação. Todas as unidades consultadas adotam linguagens documentárias na indexação para recuperação da informação.

A quarta variável, sobre oferta de serviço de resumos, investiga o uso de um dispositivo da informação sobre a informação, item de suma importância em face do agigantamento do volume de dados. Também nossa pesquisa identificaria uma preocupação do gestor da informação para com o usuário, permitindo uma busca rápida e eficiente da informação 
relevante e criando um ambiente inteligente na unidade de informação. Aqui, as unidades de informação se dividem, quase igualmente, prevalecendo, com uma pequena maioria, as unidades que não oferecem o serviço de resumos - ressalva feita à PUC, que o oferece parcialmente (apenas dissertações e teses).

A quinta variável investiga o acesso ao Portal de Periódicos da Capes, que permite à unidade de informação compartilhar de uma base de dados que tem em sua coleção uma enorme variedade de "objetos potencialmente informativos", parafraseando Buckland (1991), com a possibilidade de acesso direto a milhares de periódicos científicos do mundo inteiro. Este seria um dos sinais mais claros e evidentes de uma integração entre a unidade de informação e o ambiente da Sociedade da Informação. Desta feita, na maioria ficaram as unidades que oferecem o serviço de acesso ao Portal, ficando de fora duas universidades privadas e as bibliotecas públicas (estas por definição, já que não atendem a cientistas e pesquisadores).

Outro indício da integração da unidade de informação ao regime de informação da Sociedade da Informação, foi investigado pela sexta variável - endereço na Internet, o espaço virtual/digital por excelência. À exceção da Biblioteca Euclides da Cunha, todas têm endereço na Internet e destas apenas uma não oferece o serviço de links de interesse no sítio virtual. Podemos afirmar que todas as unidades de informação consultadas, bibliotecas universitárias e bibliotecas públicas, estão relacionadas ao ambiente do regime de informação da Sociedade da Informação, embora uma delas não apresente, ainda, endereço virtual. Dessa forma, entendemos as bibliotecas consultadas como dispositivos que cristalizam os sistemas de informação os quais, por sua vez, estão inseridos no regime de informação dominante. As ligações entre os regimes de informação e as bibliotecas são diretas, pois, a nosso ver, os regimes como modos de produção informacional têm nas bibliotecas e seus sistemas de informação uma espécie de agentes de disseminação de informação.

Entretanto, consideramos que o sistema de informação necessita estar conectado para que se realize a integração com o regime de informação dominante na Sociedade da Informação. Sob essa ótica, elaboramos a sétima variável, uma questão aberta onde perguntamos aos dirigentes dos sistemas de informação consultados sobre as vantagens e 
desvantagens das tecnologias digitais. As respostas estão reunidas no Quadro 1, em anexo.

\section{CONSIDERAÇÕES FINAIS}

Discutimos o impacto das tecnologias digitais de informação e comunicação como forma de suporte às necessidades econômicas, sociais, culturais, políticas, educacionais e informacionais da sociedade como um todo, supondo-se que essa mesma tecnologia é quem transformará e permitirá o emergir do cidadão livre e pleno (WIENER, 1984; MASUDA, 1982; TOFFLER, 1980; KUMAR, 1997).

Para a American Library Association - ALA, o ideal é criar-se uma "cultura informacional", que seria um conjunto de aptidões desenvolvidas para a resolução de problemas de informação. A cultura informacional tem na competência informacional uma ferramenta que permitiria a uma pessoa ser capaz de informar-se, ou, como esclarece a ALA, de localizar, avaliar e usar a informação com eficácia e efetividade. O caráter de cultura informacional que queremos enfatizar, é aquele instituído de forma democrática pelas organizações governamentais e não governamentais, institutos de pesquisa, bibliotecas, academias, associações religiosas, cinemas, centros culturais, museus, órgãos de comunicação, jornais, editoras - enfim, aquelas mesmas instituições que aparecem como produtoras de informação e que dão vida aos regimes de informação. A nosso ver são essas as alternativas para que o ser humano conviva de maneira equilibrada nos regimes de informação.

Todavia, o viés tecnológico vem atender, principalmente, ao excesso de informação existente e a notória dificuldade de apenas um sistema de informação dar conta de todas as áreas do conhecimento em profundidade. Nesse sentido, então, a ligação em redes é imprescindível para o atendimento às necessidades informacionais. Os sistemas de informação precisam colocar o usuário como a razão fundamental dos serviços de informação, como parte integrante do sistema, levando-se em consideração sua motivação pessoal, orientação profissional, contexto social, político, econômico, cultural, ou seja, tudo o que o afeta de maneira individual e profissional. A perspectiva de um olhar global e justo sobre o acesso à informação resultará em benefícios na participação de todos na sociedade da informação. 


\section{REFERÊNCIAS}

ARAÚJO, Vânia Maria Rodrigues Hermes de. Sistemas de informação: nova abordagem teórico-conceitual. Ciência da informação, Brasília, v.24, n.1, jan./abr.1995.

- Usuários: uma visão do problema. Belo Horizonte. Revista da Escola de Biblioteconomia da UFMG, v.3, n.2, p.175-192, set/1974.

BARRETO, Aldo de Albuquerque. A eficiência técnica e econômica e a viabilidade de produtos e serviços de informação. Ciência da Informação, Brasília, v. 25, n.3, p.405414, set/dez.1996.

BELL, Daniel. O advento da sociedade pós-industrial: uma tentativa de previsão social. São Paulo : Cultrix, 1973.

BERTALANFFY, Ludwig Von. Teoria geral dos sistemas. 2.ed. Petrópolis, RJ : Vozes, 1975.

BUCKLAND, Michael. Information as thing. Journal of the American Society for Information Science, v.42, n.5, p.351-360, 1991.

CASTELLS, Manuel. A sociedade em rede. São Paulo : Paz e Terra, 1999.(v.1; A era da informação: economia, sociedade e cultura).

DAHLBERG, Ingetraut. O futuro das linguagens de indexação. In: CONFERÊNCIA Brasileira de Classificação Bibliográfica, Rio de Janeiro, 12-17 de setembro de 1972. Anais... Brasília, DF: IBICT/ABDF, 1979, v.1. p.323-334.

DRUCKER, Peter Ferdinand. Sociedade pós-capitalista. 4.ed. São Paulo: Pioneira, 1994. 
FIGUEIREDO, Nice Menezes de. Textos avançados em referência e informação. São Paulo: Polis, 1996.

FOSKETT, Douglas John. Psicologia do usuário. In: A contribuição da psicologia para o estudo dos usuários da informação técnico-científica. Organização e tradução de Hagar Espanha Gomes. Rio de Janeiro: Calunga, 1980.

FREIRE, Isa Maria. A responsabilidade social da Ciência da informação e/ou o olhar da consciência possível sobre o campo científico. Tese (Doutorado). Rio de Janeiro: $\mathrm{CNPq} / \mathrm{IBICT}-\mathrm{UFRJ} / \mathrm{ECO}$, 2001. Disponível em: www.isafreire.pro.br. . Informação; consciência possível; campo. Um exercício com construtos teóricos. Ciência da Informação, Brasília, v.24, n.1, p. 133-142, jan/abr. 1995.

FROHMANN, Bernd. Taking information policy beyond information science: applying actor network theory. In: ANNUAL CONFERENCE OF THE CANADIAN ASSOCIATION FOR INFORMATION SCIENCE / ASSOCIATION CANADIENNE DES SCIENCES DE L'INFORMATION, 23., 1995. Edmonton. Electronic proceddings... 14p. Disponível em: http://www.cais-acsi.ca/1995proceedings.htm ou $<$ http://www.fims.uwo.ca/people/faculty/frohmann/actor.htm $>$. Acesso em: 10 maio 2005.

GONZALEZ DE GOMEZ, Maria Nélida. As relações entre ciência, Estado e sociedade: um domínio de visibilidade para as questões da informação. Ciência da Informação, Brasília, v.32, n.1, p.60-76, jan./abr.2003.

. A informação: dos estoques às redes. Ciência da informação, Brasília, v.24, n.1, jan/abr. 1995.

. Novas fronteiras tecnológicas das ações de informação: questões e abordagens. Ciência da Informação, Brasília, v.33, n.1, p.55-67, jan./abr.2004. 
KRISTEVA, Júlia. História da linguagem. Lisboa: Edições 70, 1969.

KUMAR, Krishan. Da sociedade pós-industrial à pós-moderna: novas teorias sobre o mundo contemporâneo. Rio de Janeiro: Jorge Zahar, 1997.

LAKATOS, Eva Maria. Sociologia geral. 5.ed. rev. ampl. São Paulo: Atlas, 1987.

LARA, Marilda Lopes Ginez de. O processo de construção da informação documentária e o processo de conhecimento. Perspectivas em ciência da informação, Belo Horizonte, v.7, n.2, p.127-139, jul./dez.2002.

. Linguagem documentária e terminologia. Transinformação, Campinas, v.16, n.3, p.231-240, set./dez.2004.

LARA, Marilda Lopes Ginez de, CONTI, Vivaldo Luiz. Disseminação da informação e usuários. São Paulo em Perspectiva, São Paulo, v.17, ns.3-4, 2003, p.26-34.

LE CODIAC, Yves-François. A ciência da informação. Brasília, DF: Briquet de Lemos/Livros, 1996.

LÉVY, Pierre. Cibercultura. São Paulo: Editora 34, 1999, 264p.

MACIEL, Jarbas. Elementos de teoria geral dos sistemas. Petrópolis, RJ : Vozes, 1974.

MARCONI, M. A.; LAKATOS, E. M. Técnicas de Pesquisa: planejamento e execução de pesquisas, amostragens e técnicas de pesquisas, elaboração, análise e interpretação de dados. 5. ed. São Paulo: Atlas, 2002.

MASUDA, Yoneji. A sociedade da informação como sociedade pós-industrial. Rio de Janeiro: Editora Rio, 1982.

MCLUHAN, Marshall. A galáxia de Gutenberg: a formação do homem tipográfico. 2.ed. São Paulo: Nacional, 1977. 390p. 
ORGANIZAÇÃO para a Cooperação e Desenvolvimento Econômico. OECD economic outlook. Paris, 1999.

ORTEGA, Cristina Dotta. Informação documentária: estado da arte. 2002. 259f. Dissertação. (Mestrado em Ciências da Comunicação) - Universidade de São Paulo, São Paulo, 2002.

PEREIRA, A.C. O processo de atualização técnico-científica do professor da rede municipal de ensino do Rio de Janeiro, um estudo exploratório na área de transferência da informação. Dissertação (Mest. Ci. Inf.). Rio de Janeiro: Convênio IBICT/UFRJ. 1998.

Disponível em: http://www.isafreire.pro.br/dissertacaopereira1998.pdf.

SARACEVIC, Tefko. The concept of "relevance" in Information Science: an historical review. In: Saracevic, Tefko, ed. Introduction to Information Science. New York: R. R. Bowker Co., 1970. p.11-154.

SHAFF, Adam. A Sociedade Informática. São Paulo, Brasiliense-UNESP,1992.

TÁLAMO, Maria de Fátima G. M. Linguagem documentária. São Paulo: APB, 1997.

TARAPANOFF, Kira, ARAÚJO JÚNIOR, Rogério Henrique de, CORMIER, Patrícia Marie Jeanne. Sociedade da informação e inteligência em unidades de informação. Ciência da Informação, Brasília, v.29, n.3, p.91-100. set./dez.2000

TOFFLER, Alvin. A terceira onda. 4.ed. Rio de Janeiro: Record, 1980. 491p.

UNGER, Roberto José Gervásio. Regimes de informação na sociedade da informação: uma contribuição para a gestão da informação. 2006. Dissertação [Mestr. Ci. Inf.]. Rio de Janeiro: Convênio IBICT - UFF, 2006. Disponível em: http://www.isafreire.pro.br/dissertacao_roberto_unger.pdf. 
WEBSTER, Frank. Information and the idea of an information society. In: . Theories of the information society. London: Routtedge, 1995. Cap.2, p.6-51.

WIENER, Norbert. Cibernética e sociedade: o uso humano de seres humanos. 6.ed. São Paulo: Cultrix, 1984.

WILSON, T.; STREATFIELD, D.R.; WERSIG, G. Models of the information user: progress and prospects in research. In: SWEENEY, G.P. Information and the transformation of society. Amsterdam: North Holland Pub., 1982. pag. 361-367.

\section{Roberto José Gervásio Unger}

Bibliotecário. Mestre em Ciência da Informação pelo convênio IBICT - UFF. rjgunger@gmail.com.br

\section{Isa Maria Freire}

Pesquisadora do CNPq, líder do Grupo de Pesquisa Informação e Inclusão Social do IBICT, professora no Programa de Pós-Graduação em Ciência da Informação do convênio IBICT - UFF. isa@ibict.br

\section{Recebido em: 11/03/07}

Aceito para publicação em: jun. 2007 


\section{ARTIGO}

\section{Anexo: Vantagens e desvantagens do uso das tecnologias digitais em unidades de informação}

\begin{tabular}{|c|c|c|}
\hline Unidades de informação & Vantagens das tecnologias digitais & Desvantagens das tecnologias digitais \\
\hline $\begin{array}{l}\text { PUC Rio } \\
\text { Biblioteca Central }\end{array}$ & $\begin{array}{l}\text { Maior difusão da informação; agilização nos processos de trabalho; ampliação } \\
\text { do acesso à informação, maior conforto e autonomia aos usuários da } \\
\text { informação. }\end{array}$ & $\begin{array}{l}\text { Não seriam desvantagens, mas conseqüências ou necessidades: atualização } \\
\text { dos profissionais, planejamento e organização na implantação das tecnologias } \\
\text { digitais; promoção da competência em informação aos usuários; infra- } \\
\text { estrutura de equipamentos; software e rede; política para preservação digital. }\end{array}$ \\
\hline $\begin{array}{l}\text { UFRRJ } \\
\text { Biblioteca Central }\end{array}$ & $\begin{array}{l}\text { Otimização dos serviços; Acesso mais rápido à informação; Revocação e } \\
\text { relevância; Impessoalidade. }\end{array}$ & Não foram identificadas desvantagens. \\
\hline $\begin{array}{l}\text { BEC Biblioteca } \\
\text { Euclides da Cunha }\end{array}$ & $\begin{array}{l}\text { O uso de TICs em unidades de informação propiciam aos usuários, por um lado, } \\
\text { acesso rápido e fácil a uma infinidade de informações, o que não seria possível } \\
\text { sem o uso desse tipo de tecnologia. No caso de uma Biblioteca Pública, o acesso } \\
\text { à informação utilitária, por exemplo, possibilita ao indivíduo o exercício da } \\
\text { cidadania. }\end{array}$ & $\begin{array}{l}\text { Por outro lado, essa mesma facilidade permite que qualquer tipo de } \\
\text { informação fique disponível sem verificar a idoneidade, credibilidade, } \\
\text { confiança, entre outros critérios, da informação disponibilizada na Internet. }\end{array}$ \\
\hline $\begin{array}{l}\text { BPERJ } \\
\text { Biblioteca Pública do RJ }\end{array}$ & $\begin{array}{l}\text { As tecnologias digitais possibilitam a ampliação do acesso à informação tanto } \\
\text { para o usuário presencial como para o usuário à distância. }\end{array}$ & Não foram identificadas desvantagens. \\
\hline UCAM SiBi & $\begin{array}{l}\text { Apesar da insatisfação da comunidade acadêmica com os serviços da Internet, } \\
\text { considero que as medidas tomadas para a retomada para um programa de } \\
\text { pesquisa e desenvolvimento, com o uso de novas tecnologias de informação e } \\
\text { comunicação, só trarão vantagens para pesquisadores, estudantes e profissionais } \\
\text { da informação, no tocante às facilidades eletrônicas de acesso, à universalização } \\
\text { do acesso, à agilidade, à racionalização, etc. }\end{array}$ & Não foram identificadas desvantagens. \\
\hline UFF SiBi & $\begin{array}{l}\text { Observamos que as unidades de informação que possuem infra-estrutura } \\
\text { tecnológica adequada às tecnologias digitais têm possibilitado maior interação } \\
\text { com os usuários e um atendimento mais eficaz. }\end{array}$ & $\begin{array}{l}\text { A dificuldade tem sido a morosidade na adequação da infra-estrutura e } \\
\text { pessoal capacitado das unidades de informação, para atendimento às novas } \\
\text { tendências tecnológicas que são indispensáveis no mundo atual. }\end{array}$ \\
\hline
\end{tabular}




\section{ARTIGO}

\begin{tabular}{|c|c|c|}
\hline UFRJ SiBi & $\begin{array}{l}\text { Rapidez, maior visibilidade temporal (acesso à edições anteriores numa mesma } \\
\text { pesquisa), grande abrangência, diversidade de resultados (imprimir, copiar, } \\
\text { enviar, salvar), possibilidade de uso de recursos sofisticados de busca. No caso } \\
\text { de obras raras, preservação, facilidade de divulgação. }\end{array}$ & $\begin{array}{l}\text { Requer investimentos pesados em computadores para otimizar a consulta; } \\
\text { treinamentos permanentes dos usuários, servidores (hardware) mais potentes } \\
\text { como repositórios da informação digital, eficiente rede de transmissão de } \\
\text { dados. }\end{array}$ \\
\hline \begin{tabular}{|l} 
UniCarioca \\
(Biblioteca local)
\end{tabular} & $\begin{array}{l}\text { A utilização da tecnologia digital tem como grande vantagem, no meu ponto de } \\
\text { vista, a facilidade de acesso à informação independente da localização física e } \\
\text { geográfica. Considero que mais do que simplesmente recursos de informação, as } \\
\text { novas tecnologias disponíveis na Internet, são acima de tudo ferramentas que } \\
\text { abrem novas possibilidades de conhecimento. }\end{array}$ & Não foram identificadas desvantagens. \\
\hline UniverCidade SiBi & $\begin{array}{l}\text { Possibilidades de acesso remoto, recuperação com precisão e de forma rápida, } \\
\text { uniformidade na descrição do item documental, possibilidade de migração de } \\
\text { dados de outras bases. }\end{array}$ & $\begin{array}{l}\text { Necessidade de treinamento do pessoal (de atendimento e de usuários), } \\
\text { obrigatoriedade de novos e constantes investimentos pelo rápido } \\
\text { desenvolvimento das tecnologia. }\end{array}$ \\
\hline $\begin{array}{l}\text { Universo } \\
\text { Biblioteca Niterói }\end{array}$ & $\begin{array}{l}\text { As vantagens são totais e visíveis, hoje a informação transita com muita rapidez } \\
\text { e precisão, ferramenta de apoio à pesquisa, ao ensino e extensão. Porém um } \\
\text { sistema só funciona na sua totalidade quando interligado em rede, para que } \\
\text { todos possam partilhar e participar. A biblioteca é um organismo muito } \\
\text { dinâmico, flutuante e os sistemas de informação só agregaram valor aos serviços } \\
\text { prestados aos nossos usuários. }\end{array}$ & Não foram identificadas desvantagens. \\
\hline UVA SiBi & Evidentemente as tecnologias digitais oferecem inúmeras vantagens. & $\begin{array}{l}\text { Como desvantagem constata-se a realidade brasileira, nem todos fazem uso } \\
\text { da tecnologia em questão, o que nos força a pensar que no futuro, a situação } \\
\text { dos usuários e dos recursos técnicos (energia, idade dos computadores e do } \\
\text { software) facilitem a todos. }\end{array}$ \\
\hline
\end{tabular}

